\title{
A Home-Based eHealth Intervention for an Older Adult Population With Food Insecurity: Feasibility and Acceptability Study
}

Luís Antunes Gomes ${ }^{1,2}$, MSc; Maria João Gregório ${ }^{1,2,3}, \mathrm{PhD}$; Tatiana A Iakovleva ${ }^{4}, \mathrm{PhD}$; Rute Dinis de Sousa ${ }^{1,2}$, MSc, MBA; John Bessant ${ }^{5}$, PhD; Pedro Oliveira ${ }^{6,7}, \mathrm{PhD}$; Jaime C Branco ${ }^{1,2,8}, \mathrm{MD}, \mathrm{PhD}$; Helena Canhão ${ }^{1,2}$, MD, PhD; Ana Maria Rodrigues ${ }^{1,2}, \mathrm{MD}, \mathrm{PhD}$

${ }^{1}$ Comprehensive Health Research Centre, NOVA Medical School, Universidade NOVA de Lisboa, Lisbon, Portugal

${ }^{2}$ EpiDoC Unit, Centro de Estudos de Doenças Crónicas, NOVA Medical School, Universidade NOVA de Lisboa, Lisbon, Portugal

${ }^{3}$ Faculdade de Ciências da Nutrição e Alimentação da Universidade do Porto, Porto, Portugal

${ }^{4}$ Stavanger Business School, Stavanger, Norway

${ }^{5}$ University of Exeter Business School, Exeter, United Kingdom

${ }^{6}$ Copenhagen Business School, Copenhagen, Denmark

${ }^{7}$ NOVA School of Business and Economics, Universidade NOVA de Lisboa, Lisbon, Portugal

${ }^{8}$ Serviço de Reumatologia do Hospital Egas Moniz - Centro Hospitalar Lisboa Ocidental (CHLO-EPE), Lisbon, Portugal

\section{Corresponding Author:}

Ana Maria Rodrigues, MD, PhD

Comprehensive Health Research Centre

NOVA Medical School

Universidade NOVA de Lisboa

Pólo de Investigação, NMS, UNL. Edifício Amarelo

Piso 2. Rua do Instituto Bacteriológico, nº5

Lisbon

Portugal

Phone: 351218803000

Email: ana.m.rodrigues@nms.unl.pt

\section{Abstract}

Background: Food insecurity is a global public health challenge, affecting predominately the most vulnerable people in society, including older adults. For this population, eHealth interventions represent an opportunity for promoting healthy lifestyle habits, thus mitigating the consequences of food insecurity. However, before their widespread dissemination, it is essential to evaluate the feasibility and acceptability of these interventions among end users.

Objective: This study aims to explore the feasibility and acceptability of a home-based eHealth intervention focused on improving dietary and physical activity through an interactive television (TV) app among older adults with food insecurity.

Methods: A pilot noncontrolled quasi-experimental study was designed with baseline and 3-month follow-up assessments. Older adult participants with food insecurity were recruited from 17 primary health care centers in Portugal. A home-based intervention program using an interactive TV app aimed at promoting healthy lifestyle behaviors was implemented over 12 weeks. Primary outcomes were feasibility (self-reported use and interest in eHealth) and acceptability (affective attitude, burden, ethicality, perceived effectiveness, and self-efficacy), which were evaluated using a structured questionnaire with a 7-point Likert scale. Secondary outcomes were changes in food insecurity (Household Food Insecurity Scale), quality of life (European Quality of Life Questionnaire with five dimensions and three levels and Functional Assessment of Chronic Illness Therapy-Fatigue), physical function (Health Assessment Questionnaire, Elderly Mobility Scale, grip strength, and regularity of exercise), and nutritional status (adherence to the Mediterranean diet).

Results: A sample of 31 older adult individuals with food insecurity was enrolled in the 12-week intervention program with no dropouts. A total of 10 participants self-reported low use of the TV app. After the intervention, participants were significantly more interested in using eHealth to improve food insecurity (baseline median 1.0, IQR 3.0; 3-month median 5.0, IQR 5.0; $P=.01$ ) and for other purposes (baseline median 1.0, IQR 2.0; 3-month median 6.0, IQR 2.0; $P=.03$ ). High levels of acceptability were found both before and after (median range 7.0-7.0, IQR 2.0-0.0 and 5.0-7.0, IQR 2.0-2.0, respectively) the intervention, with no significant changes for most constructs. Clinically, there was a reduction of $40 \%$ in food insecurity $(P=.001)$, decreased fatigue 
(mean -3.82, SD 8.27; $P=.02$ ), and improved physical function (Health Assessment Questionnaire: mean -0.22, SD 0.38; $P=.01$; Elderly Mobility Scale: mean -1.50 , SD 1.08; $P=.01$; regularity of exercise: baseline 10/31, 32\%; 3 months $18 / 31,58 \% ; P=.02$ ). No differences were found for the European Quality of Life Questionnaire with five dimensions and three levels, grip strength, or adherence to the Mediterranean diet.

Conclusions: The home-based eHealth intervention was feasible and highly acceptable by participants, thus supporting a future full-scale trial. The intervention program not only reduced the proportion of older adults with food insecurity but also improved participants' fatigue and physical function.

International Registered Report Identifier (IRRID): RR2-10.2196/resprot.6626

(J Med Internet Res 2021;23(8):e26871) doi: 10.2196/26871

\section{KEYWORDS}

food insecurity; eHealth; television app; elderly people; vulnerable population; cognitive behavioral strategy; health innovation; multidisciplinary program

\section{Introduction}

\section{Background}

Food security is an essential prerequisite for a population to be healthy, active, and well-nourished. According to the World Health Organization, food security exists "when all people, at all times, have physical, social and economic access to sufficient, safe and nutritious food that meets their dietary needs and food preferences for an active and healthy life" [1]. As a comprehensive concept, food security depends on four essential dimensions: physical availability of food, economic and physical access to food, food use and maximization of consumption, and stability at all times [1]. When one or more of these dimensions are compromised, people or households are assumed to have food insecurity.

The multidimensional and self-perceived nature of food insecurity makes quantification challenging. Among the various instruments, the Household Food Insecurity Scale developed by the United States Department of Agriculture (USDA) is the most widely used tool in epidemiological studies [2,3]. This instrument classifies the food insecurity status of an entire household while considering multiple dimensions using a simple, easy, and validated approach [3].

Food insecurity is a global public health problem. Despite mainly affecting low-income countries, increasing evidence suggests that food insecurity is also highly prevalent in high-income countries [4]. For example, in the United States, one of the richest nations in the world, a USDA report states that $10.5 \%$ of households were facing food insecurity in 2019 [2]. Although this represents a lower prevalence since the Great Recession of 2008, the economic downturn caused by the COVID-19 pandemic may trigger an unprecedented food insecurity crisis [5,6]. National estimates in March and April 2020 indicate that the prevalence of this problem has more than tripled to $38 \%$, which is the highest level of food insecurity ever measured in the United States [7].

In Europe, particularly Portugal, a country still recovering from an economic crisis, the impact of the COVID-19 pandemic is uncertain. The current economic, political, and social instability in this country may have overwhelming consequences, especially for individuals who are physically, economically, and socially vulnerable, such as older adults. Indeed, the prevalence of food insecurity among older adults is remarkably high, with a study from our group reporting that $23 \%$ of older Portuguese people experienced food insecurity in 2015 and 2016, which is higher than the prevalence among adults $[8,9]$.

The consequences of food insecurity among older adults present major challenges to the society. The aging of this population, which has a poor overall health status, physical comorbidities, limited family contact or assistance, and low income, can compromise the motivation of older adults to adopt health behaviors that are compatible with an active and healthy lifestyle, particularly those related to a healthy diet and physical activity. For this population, which has special nutritional needs, food insecurity is associated with a poor nutritional status, physical disability, muscle weakness, depression and anxiety symptoms, and lower health-related quality of life (HRQoL), which in turn increases vulnerability to other conditions, hospitalization, and death [9-14].

Developing strategies to mitigate the consequences of food insecurity among older adults is essential for increasing their quality of life and well-being. However, the unique characteristics of this population make it difficult to conduct an experimental study, leaving this particularly vulnerable and growing population with low access to health care innovation.

The promotion of healthy lifestyle habits and the resulting increase in well-being and quality of life among older adults could be addressed by eHealth interventions, which are defined as the use of information and communication technologies (ICTs) for health [15]. These interventions are low-cost, personalized approaches capable of increasing the autonomy of older adults and their access to quality health care [16-18]. Emerging evidence shows that eHealth interventions for older adults have delivered promising results in terms of improving nutritional status [19] and physical activity [20,21] and have positive clinical outcomes for specific conditions such as fragility fracture [22] and cardiovascular disease [23]. However, unique characteristics of the lifestyle of older adults should be acknowledged to overcome the associated barriers before the wider implementations of eHealth interventions [18,19,24].

Among the available ICTs, television (TV) is the device mostly used by older people [25]. As most older people's houses have a TV, this device could present an opportunity to successfully design and implement eHealth interventions aimed at promoting 
healthy lifestyles with their daily life. By improving the nutritional status and physical activity levels, a TV home-based program might slow the decline in physical function and increase the well-being and quality of life among older adults experiencing food insecurity.

To promote healthy lifestyles among older adults with food insecurity, we designed a home-based intervention program using an interactive TV app [26]. Following the new Medical Research Council's guidance for developing and evaluating complex interventions [27], a multidisciplinary team of health professionals (ie, physicians, nurses, nutritionists, and physiotherapists), physical exercise experts, telecommunications companies, stakeholders, and end users collaboratively developed the conceptual framework of the program (Figure 1). In this development process, 11 older adult participants in a focus group reported high app usability, adherence intention, and the expected impact of the program on behavior modification [26]. All aspects of program conception considered ethical, social, economic, cultural, and environmental implications for all stakeholders, as suggested by the Responsible Innovation Framework [28].

Figure 1. Conceptual framework of the program. TV: television.

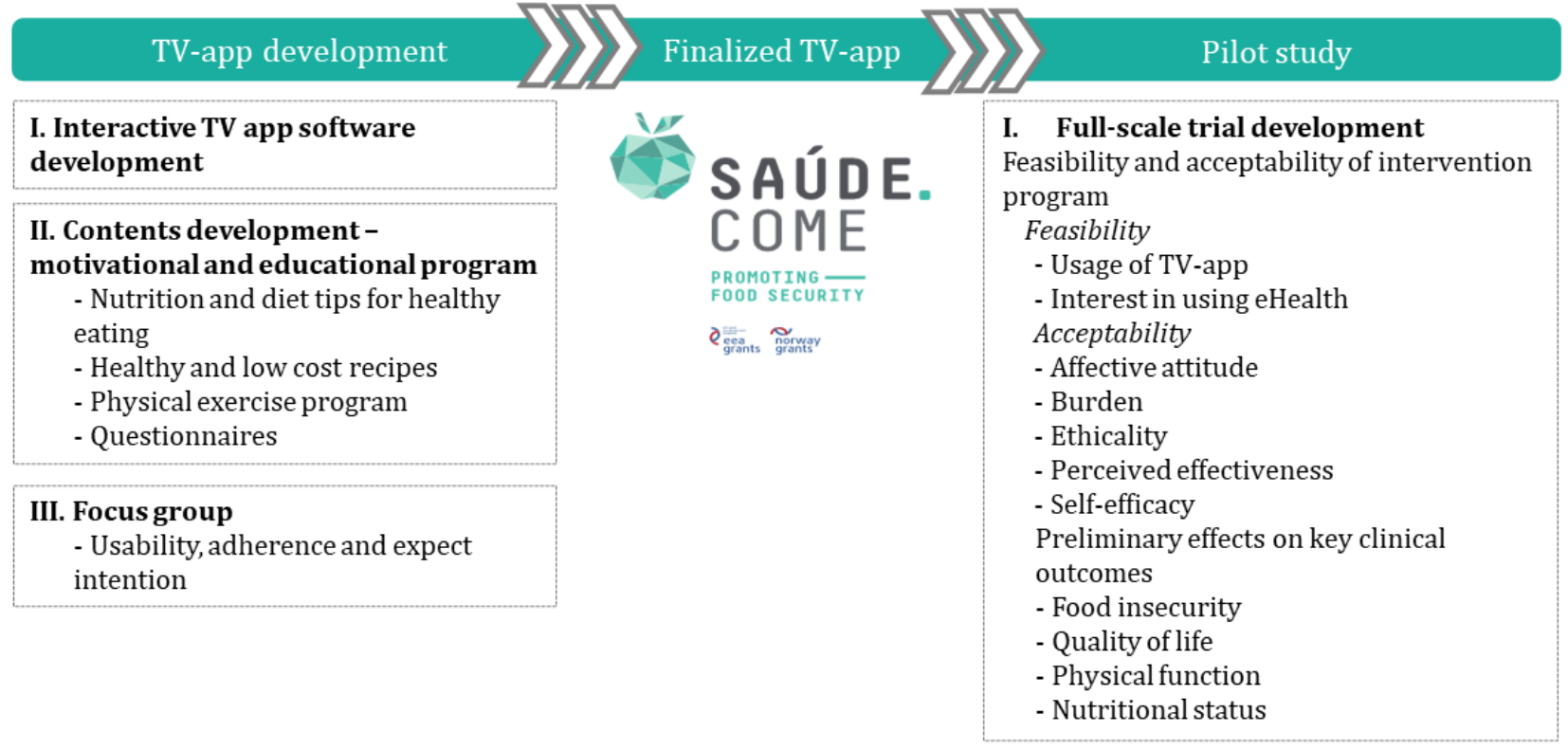

\section{Objectives}

After the conclusion of the TV app development process [26], the next step was to analyze the feasibility and acceptability of this intervention program in a pilot study. The primary aim of this pilot study is to test the feasibility and acceptability of a multidisciplinary 12-week home-based intervention program focused on improving dietary and physical activities through an interactive TV app among older adults with food insecurity. The secondary aim is to assess changes in the key clinical outcomes at the 3-month follow-up. The results of this pilot study are crucial for understanding end users' interest and use of the TV app along with the suitability of the program to their needs.

\section{Methods}

\section{Research Design}

This pilot study used a noncontrolled quasi-experimental design with before and after measurements. Program feasibility, acceptability, and key clinical outcomes were evaluated at baseline and at the 3-month follow-up after the completion of the eHealth intervention. Older adult participants aged 60 years or above were recruited from 17 primary health care centers in the Lisboa e Vale do Tejo health region in Portugal.

\section{Participants}

A convenience sample of older adults with food insecurity from 17 primary care centers in Lisboa e Vale do Tejo health region was used in this study. Individuals were included if they (1) were aged 60 years or above, (2) were classified as having food insecurity during recruitment [29], (3) were able and willing to give written informed consent and a phone number contact and comply with other requirements of the study protocol, (4) were a Portuguese speaker or able to understand Portuguese, (5) were noninstitutionalized and living in a private household in Portugal, (6) had electricity at home, and (7) had cable TV with a box at home. Individuals were excluded if they (1) were unable to comply with the study protocol (eg, hearing or visual loss and cognitive impairment), (2) had an absolute contraindication to exercise, (3) had cable TV operated by a company other than MEO, Vodafone, or NOS, and (4) had a household member involved in the study. Participants were recruited between November 2015 and May 2016. During the recruitment phase, all older adults who attended health services in the selected primary health care centers were invited to complete an initial screening questionnaire, which included a food insecurity scale [29]. Participants who agreed to complete the questionnaire were asked to provide their consent for further contact. All participants who identified as having food insecurity were invited to participate in this study. In case of acceptance, the first baseline assessment appointment was scheduled. This 
occurred during an appointment in a primary health care setting with a multidisciplinary team that included a physician, nurse, nutritionist, and physiotherapist. The physician asked for informed consent and checked the eligibility criteria.

\section{Intervention}

A detailed description of the intervention can be found in a previous study [26], which briefly comprised a 12-week home-based intervention focused on the innovative use of an interactive TV app. The design of the intervention program was based on a transtheoretical model of behavior change [30] and aimed to promote lifestyle behavior changes among older individuals with food insecurity by (1) providing education on the importance of a healthy diet and physical activity among older adults, (2) demonstrating that low household income is not a barrier to healthy lifestyle habits and that it is possible to have a healthy diet and practice physical activity at low cost, and (3) providing motivation for adopting a healthy diet and physical activity habits to reduce noncommunicable diseases. The pillars of program content were divided into nutrition and diet tips for healthy eating, low-cost healthy recipes, and physical exercise programs. Different contents were specifically structured based on the thematic weeks. The themes for each week and the respective content of each video were developed by considering the different types of food most frequently used in daily life routine (eg, vegetables, water, and milk). Nutrition and diet tips were based on the explanations of the benefits and harms of eating certain foods, especially regarding their relationship with risk factors for noncommunicable diseases and nutritional requirements for older adults [31-34]. Low-cost healthy recipes were specifically designed for our program using a popular Portuguese TV chef and a nutritionist. Finally, the physical activity program was developed by physical exercise experts with the specific objective of promoting the practice of physical activity at home for at least 30 minutes thrice a week [35].

All program content was disseminated on a dedicated TV channel via the interactive TV app and delivered on a scheduled basis on specific days of the week for developing a program access routine. To increase the participants' motivation, interactive TV reminders, including tips about healthy lifestyle habits, were sent on a weekly basis. In addition, participants had at their disposal the teams' telephone numbers and options to contact them whenever necessary. The research team also made frequent contact with the participants to increase their adherence and overcome difficulties. The TV app software included the delivery of small questionnaires aimed at assessing participants' compliance and learning during the intervention program. These questionnaires were delivered on a weekly basis and could be answered using TV remote control buttons. Any participant who opened the TV app fewer than 2 times during the intervention period was excluded from the data analysis.

\section{Outcomes}

\section{Overview}

The primary outcomes were feasibility and acceptability of the intervention program. Secondary outcomes were changes in food insecurity, quality of life, physical function, and nutritional status after the intervention.

Data were collected using a structured questionnaire administered at two time points: before the intervention at study enrollment (baseline) and 3 months after the intervention (follow-up). The baseline assessment was performed by a multidisciplinary team (ie, physicians, nurses, nutritionists, and physiotherapists) at the primary care centers involved in the study using a computer-assisted personal interview system. At the 3-month follow-up, the assessment was performed by telephone using a computer-assisted personal interview system by a team of trained research assistants.

\section{Baseline Characteristics}

During baseline assessment, information was collected regarding sociodemographic (ie, gender, age, years of education, and marital status), socioeconomic (ie, employment status, household composition, household monthly income, and income perception), clinical (ie, food insecurity, BMI $\left[\mathrm{kg} / \mathrm{m}^{2}\right]$, anxiety and depression symptoms measured using the Hospital Anxiety and Depression Scale [36], and self-reported noncommunicable chronic diseases), and lifestyle characteristics (ie, alcohol intake profile, smoking habits, PREDIMED [Prevención con Dieta Mediterránea] score, perceptions of the importance and difficulty of healthy eating, frequency of watching TV, frequency of computer, videogame, tablet use, and frequency of internet use).

\section{Feasibility and Acceptability of the Intervention Program}

The measures of feasibility of the intervention program were (1) self-reported use of the TV app evaluated at 3-month follow-up and (2) interest in the use of eHealth evaluated with a structured questionnaire administered pre- (baseline) and postintervention (3-month follow-up). This questionnaire was also used to evaluate the acceptability of the intervention program. The acceptability evaluation was based on the theoretical framework of acceptability and included the following component constructs: affective attitude ("how an individual feels about the intervention"), burden ("perceived amount of effort required to participate in the intervention"), ethicality ("extent to which the intervention has good fit with an individuals' value system"), perceived effectiveness ("extent to which the intervention is perceived as likely to achieve its purpose"), and self-efficacy ("individuals' confidence that they can perform the behaviors required to participate in the intervention") [37]. The structured questionnaire included 16 questions rated on a 7-point Likert scale with scores ranging from 1 (strongly negative/completely disagree) to 7 (strongly positive/completely agree). To understand participants' perceptions in greater detail, the questionnaire included 3 additional questions using an open question approach to evaluate the most liked and disliked content of the intervention program (affective attitude construct) and the greatest difficulties in using the TV app (burden construct). Participants who initially self-reported low use of the TV app were not included in the evaluation of the interest construct of feasibility or the acceptability of the intervention program, as their experience with the TV app was limited. The reasons for the low use of the TV app were assessed using an open question approach. 


\section{Food Insecurity, Quality of Life, Physical Function, and Nutritional Status}

Secondary outcomes were changes in food insecurity, quality of life, physical function, and nutritional status after the intervention. Food insecurity was measured using the Household Food Insecurity Scale, a scale adapted and validated for the Portuguese population from the USDA Household Food Security Survey Module [29]. The tool is applied at the individual level and collects data on food insecurity status for the whole household. Using a score ranging from 0 to 14 , households were classified into different categories of food insecurity: food security (score of 0 ), low food insecurity (score between 1 and 5 for households with children and between 1 and 3 for households without children), moderate food insecurity (score between 6 and 9 for households with children and between 4 and 5 for households without children), and severe food insecurity (score between 10 and 14 for households with children and between 6 and 8 for households without children) [29].

Quality of life was evaluated using two different measures. The European Quality of Life Questionnaire with five dimensions and three levels (EQ-5D-3L) was used to measure HRQoL [38,39]. A higher EQ-5D-3L score corresponded to a higher quality of life. The Functional Assessment of Chronic Illness Therapy-Fatigue (FACIT-F) was used to evaluate fatigue in patients with chronic diseases [40]. This score ranges from 0 to 52 , with higher scores representing less fatigue.

The physical function was evaluated using several instruments. The functional ability of the individuals was measured using the Health Assessment Questionnaire (HAQ) [41,42]. The final HAQ score ranges from 0 to 3 points, with higher scores corresponding to a lower functional ability. The Elderly Mobility Scale (EMS) was used to evaluate the performance and mobility of participants and has a score ranging from 0 to $20[43,44]$, with higher scores indicating a greater degree of independence or mobility. A dynamometer was used to measure hand grip strength (lbs). Finally, data concerning exercise regularity (yes or no) and frequency $(0,1-2,2-4$, or $\geq 5$ exercise sessions per week for a duration of at least 45 minutes) were recorded.

Nutritional status was classified based on the PREDIMED questionnaire, a 14-item questionnaire assessing adherence to the Mediterranean diet (MD) [8]. A score of $\geq 10$ points indicated a high adherence to $\mathrm{MD}$, and a score $<10$ points indicated a low adherence to MD [45].

\section{Statistical Analysis}

The results were analyzed using SPSS Statistics (version 26.0, IBM Corp). Continuous variables are reported as mean and SD. Categorical variables are reported as frequencies or proportions. Changes in the feasibility and acceptability of the intervention program between baseline and 3-month follow-up are reported as median and IQR. The Wilcoxon signed-rank test or Sign test was used to assess differences after the intervention regardless of whether the data were symmetric. Differences in food insecurity, quality of life, physical function, and nutritional status between baseline and 3-month follow-up were assessed depending on the type of variable (continuous or ordinal), normal distribution, and data symmetry. The food insecurity results are summarized as frequencies and proportions in a contingency table. The Sign test was used to assess the differences between pre- and postintervention, as all participants had food insecurity at baseline. EQ-5D-3L, FACIT-F, HAQ, EMS, and hand grip strength data are reported as mean and SD, and differences at 3-month follow-up were evaluated using a 2-tailed paired $t$ test, Wilcoxon signed-rank test, or Sign test. Regularity of exercise (yes or no) and PREDIMED (low or high adherence to $\mathrm{MD}$ ) results were analyzed using frequencies and proportions in a contingency table, and differences were evaluated using McNemar tests for paired binary data. A significance level of $5 \%$ was considered as statistically significant.

\section{Ethical Issues}

The study was performed in accordance with the principles established by the Declaration of Helsinki and was reviewed and approved by the NOVA Medical School Ethics Committee, the National Committee for Data Protection (Comissão Nacional de Proteção de Dados), and the Ethical Committee of the Regional Health Authority of Lisboa e Vale do Tejo.

\section{Results}

\section{Baseline Characteristics}

During the 7-month recruitment period, 1857 individuals were screened at primary health care centers, 628 of whom were classified as having food insecurity. Of these, 177 older adult participants were identified as potentially eligible for the study; however, most did not agree to participate $(73 / 177,41.2 \%)$ or missed the medical appointment $(45 / 177,25.4 \%)$. Several participants $(21 / 177,11.9 \%)$ were excluded because of technological incompatibilities with the interactive TV app installation or software (Figure 2). Table 1 presents the participants' baseline sociodemographic, socioeconomic, clinical, and lifestyle characteristics $(n=31)$. The participants were predominantly female $(21 / 31,68 \%)$ with a mean age of 71.9 (SD 6.6) years and a low education profile (10/23, 43\%). Most participants were retired (24/30,80\%), lived in a household with 3 or more people $(9 / 23,39 \%)$, and had a very low monthly income $(13 / 23,57 \%)$. Clinically, $50 \%(11 / 22)$ of the participants were obese, and most had chronic noncommunicable diseases. Regarding lifestyle, only $32 \%$ (10/31) were physically active and $90 \%(19 / 21)$ reported low adherence to MD. All participants acknowledged the importance of healthy eating $(22 / 22,100 \%)$, despite recognizing the associated difficulties $(10 / 22,45 \%)$. Finally, with a predominant watching frequency of 2-3 hours per day $(13 / 31,42 \%)$, TV was the predominantly used ICTs by participants. No participants were excluded from the data analysis at the 3-month follow-up. 
Figure 2. Participant recruitment and retention flowchart. TV: television.

Participants identified as being (1) aged 60 years or older; (2) food insecure; (3) able and willing to give written informed consent and phone number; (4) Portuguese speaker

or able to understand Portuguese; (5) noninstitutionalized and living in a private household in Portugal; and having (6) electricity at home; and (7) cable TV with box at home. Participants could not have (1) the inability to comply with study protocol (no hearing or visual loss, cognitive impairment, etc); (2) an absolute contraindication to exercise; (3) cable TV operated by other company than MEO, Vodafone, or NOS; or (4) a household member involved in this study.

( $\mathrm{N}=177$ )

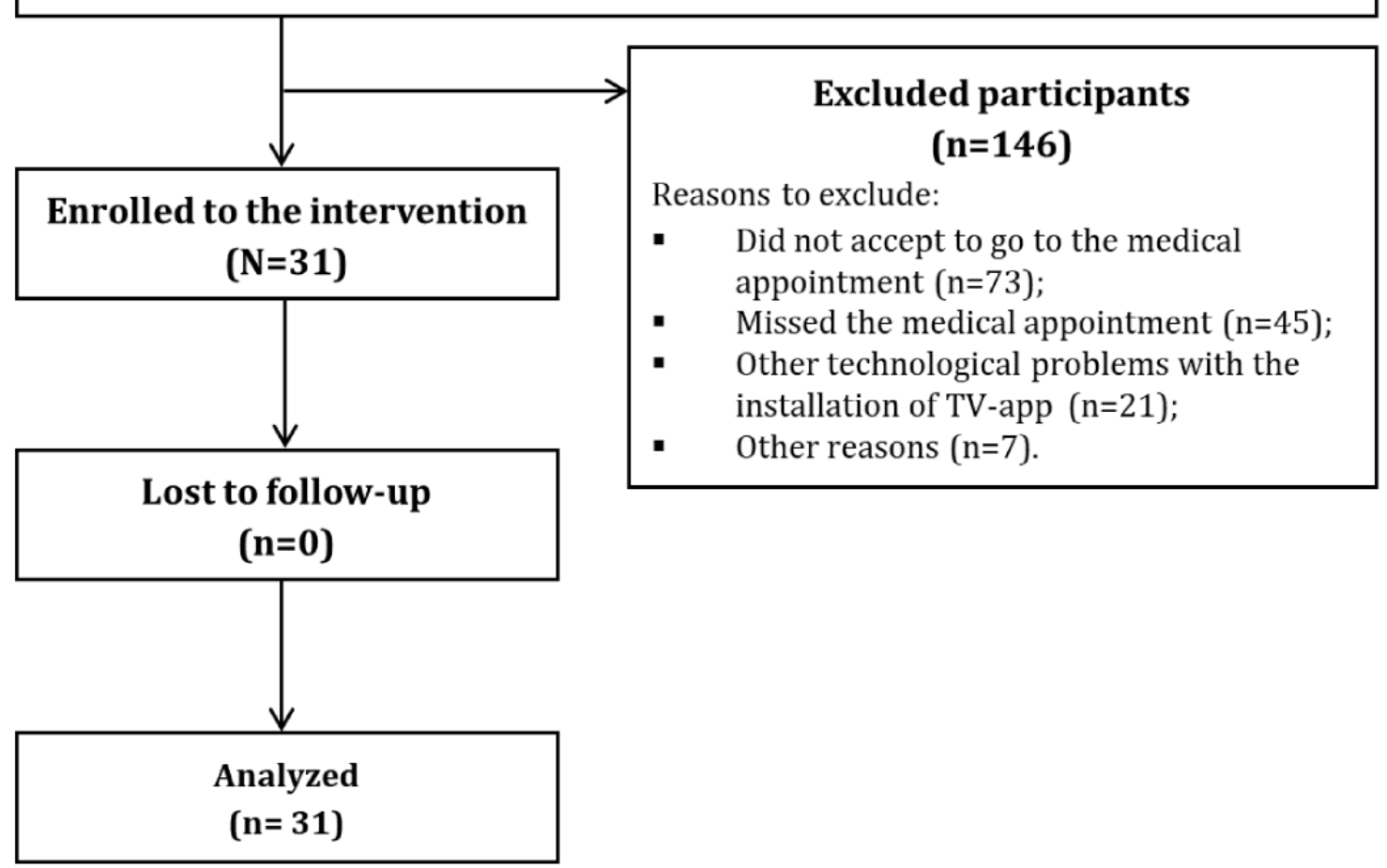


Table 1. Baseline sociodemographic, socioeconomic, clinical, and lifestyle characteristics of participants $(\mathrm{N}=31)^{\mathrm{a}}$.

\begin{tabular}{|c|c|}
\hline Characteristics & Values \\
\hline \multicolumn{2}{|l|}{ Sociodemographic } \\
\hline \multicolumn{2}{|l|}{ Gender (n=31), n (\%) } \\
\hline Female & $21(68)$ \\
\hline Age (years; $n=31$ ), mean $(\mathrm{SD})$ & $71.9(6.6)$ \\
\hline \multicolumn{2}{|l|}{ Age group (years; $n=31), n(\%)$} \\
\hline $60-69$ & $15(48)$ \\
\hline $70-79$ & $10(32)$ \\
\hline$\geq 80$ & $6(19)$ \\
\hline \multicolumn{2}{|l|}{ Years of education $(n=23), n(\%)$} \\
\hline $0-4$ & $10(43)$ \\
\hline $5-9$ & $6(26)$ \\
\hline$\geq 10$ & $7(30)$ \\
\hline \multicolumn{2}{|l|}{ Marital status $(\mathrm{n}=\mathbf{2 4}), \mathrm{n}(\%)$} \\
\hline Single & $3(13)$ \\
\hline Married & $13(54)$ \\
\hline Divorced & $6(25)$ \\
\hline Widow or widower & $2(8)$ \\
\hline \multicolumn{2}{|l|}{ Socioeconomic, $\mathbf{n}(\%)$} \\
\hline \multicolumn{2}{|l|}{ Employment status (n=30) } \\
\hline Employed & $1(3)$ \\
\hline Unemployed & $5(17)$ \\
\hline Retired & $24(80)$ \\
\hline \multicolumn{2}{|l|}{ Household composition $(\mathrm{n}=\mathbf{2 3})$} \\
\hline 1 person & $8(35)$ \\
\hline 2 people & $6(26)$ \\
\hline$\geq 3$ people & $9(39)$ \\
\hline \multicolumn{2}{|l|}{ Household monthly income ( $€$; US \$; n=23) } \\
\hline$\leq 750(880.63)$ & $13(57)$ \\
\hline $751-1000(881.80-1174.17)$ & $5(22)$ \\
\hline$>1000(1174.17)$ & $5(22)$ \\
\hline \multicolumn{2}{|l|}{ Income perception $(n=23)$} \\
\hline I live comfortably with my current income & $1(4)$ \\
\hline I can live with my current income & $7(30)$ \\
\hline It is difficult to live with my current income & $7(30)$ \\
\hline It is very difficult to live with my current income & $8(35)$ \\
\hline \multicolumn{2}{|l|}{ Clinical, n (\%) } \\
\hline \multicolumn{2}{|l|}{ Food insecurity $(n=31)$} \\
\hline Food security & $0(0)$ \\
\hline Food insecurity & $31(100)$ \\
\hline Low food insecurity & $27(87)$ \\
\hline Moderate food insecurity & $3(10)$ \\
\hline Severe food insecurity & $1(3)$ \\
\hline
\end{tabular}




\begin{tabular}{|c|c|}
\hline Characteristics & Values \\
\hline \multicolumn{2}{|l|}{ BMI $\left(\mathrm{kg} / \mathrm{m}^{2} ; \mathrm{n}=22\right)$} \\
\hline Underweight & $0(0)$ \\
\hline Normal weight & $3(14)$ \\
\hline Overweight & $8(36)$ \\
\hline Obesity & $11(50)$ \\
\hline \multicolumn{2}{|l|}{ Anxiety and depression symptoms $(n=23)$} \\
\hline Anxiety symptoms $\left(\mathrm{HADS}^{\mathrm{b}}\right.$ score $\geq 11$ ) & $7(30)$ \\
\hline Depression symptoms (HADS score $\geq 11$ ) & $3(13)$ \\
\hline \multicolumn{2}{|l|}{ Noncommunicable chronic diseases (self-reported; $\mathbf{n = 3 1}$ ) } \\
\hline Rheumatic disease & $20(65)$ \\
\hline High blood pressure & $17(55)$ \\
\hline Diabetes & $7(23)$ \\
\hline High cholesterol & $12(39)$ \\
\hline Pulmonary disease & $2(6)$ \\
\hline Cardiac disease & $5(16)$ \\
\hline Gastrointestinal disease & $3(10)$ \\
\hline Neurologic disease & $4(13)$ \\
\hline Neoplastic disease & $3(10)$ \\
\hline Thyroid or parathyroid disease & $5(16)$ \\
\hline Other diseases (eg, ophthalmic, dermatologic, or auditory) & $3(10)$ \\
\hline \multicolumn{2}{|l|}{ Lifestyle habits, n (\%) } \\
\hline \multicolumn{2}{|l|}{ Physical activity $(n=31)$} \\
\hline Regular & $10(32)$ \\
\hline \multicolumn{2}{|l|}{ Alcohol intake profile $(\mathbf{n}=\mathbf{2 3})$} \\
\hline Daily & $2(9)$ \\
\hline Occasionally & $12(52)$ \\
\hline Never & $9(39)$ \\
\hline \multicolumn{2}{|l|}{ Smoking habits $(\mathrm{n}=31)$} \\
\hline Current smoker & $4(13)$ \\
\hline Past smoker & $9(29)$ \\
\hline Never & $18(58)$ \\
\hline \multicolumn{2}{|l|}{ PREDIMED $^{c}(n=21)$} \\
\hline Low adherence to $\mathrm{MD}^{\mathrm{d}}$ & $19(90)$ \\
\hline High adherence to MD & $2(10)$ \\
\hline \multicolumn{2}{|l|}{ Perceptions about the importance of healthy eating $(n=22)$} \\
\hline Without or with little importance & $0(0)$ \\
\hline Neither important nor unimportant & $0(0)$ \\
\hline Important or very important & $22(100)$ \\
\hline \multicolumn{2}{|l|}{ Perceptions about the difficulty of healthy eating $(n=22)$} \\
\hline Difficult or very difficult & $10(45)$ \\
\hline Neither difficult nor easy & $3(14)$ \\
\hline Easy or very easy & $9(41)$ \\
\hline
\end{tabular}




\begin{tabular}{ll}
\hline Characteristics & Values \\
\hline Frequency of watching $\mathbf{T V}^{\mathbf{e}}(\mathbf{n}=\mathbf{3 1})$ & $1(3)$ \\
$\quad$ Does not watch & $6(19)$ \\
$\leq 1$ hours/day & $13(42)$ \\
$2-3$ hours/day & $11(35)$ \\
$\geq 4$ hours/day & \\
Frequency of computer, videogame, or tablet use $(\mathbf{n}=\mathbf{3 1})$ & $16(52)$ \\
Does not use & $6(19)$ \\
$\leq 1$ hours/day & $7(23)$ \\
$2-3$ hours/day & $2(6)$ \\
$\geq 4$ hours/day & \\
Frequency of internet use $(\mathbf{n}=\mathbf{3 1})$ & $16(52)$ \\
Does not use & $8(26)$ \\
$\leq 1$ hours/day & $6(19)$ \\
$2-3$ hours/day & $1(3)$ \\
$\geq 4$ hours/day &
\end{tabular}

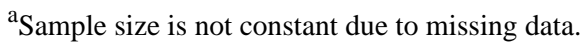

${ }^{b}$ HADS: Hospital Anxiety and Depression Scale.

${ }^{\mathrm{c}}$ PREDIMED: Prevención con Dieta Mediterránea.

${ }^{\mathrm{d}} \mathrm{MD}$ : Mediterranean diet.

$\mathrm{e}_{\mathrm{TV}}$ : television.

\section{Feasibility and Acceptability of the Intervention Program}

After the intervention program, some participants $(n=10)$ self-reported low use of the TV app, and thus did not provide answers to the feasibility construct "interest in using eHealth" or acceptability questions. The reasons for the low use of the TV app were "lack of interest" $(n=2)$, "lack of time" $(n=2)$, "much time away from home during the intervention period" $(n=2)$, "complications with the software" $(n=1)$, or "health reasons" $(\mathrm{n}=1)$. Two participants did not provide a reason. Despite these results, all participants opened the TV app two or more times, and none were excluded from the data analysis of clinical outcome.
Regarding participants' interest in using eHealth, a considerable increase was observed both for the treatment of food insecurity and other purposes.

Acceptability constructs showed very high scores both at baseline and at the 3-month follow-up, with no significant changes for most items (Table 2). However, "interest in using the TV app in daily life," "attractiveness of using the TV app in daily life," "advantages of using the TV app are/were higher than disadvantages," and "ability of the TV app to solve challenges/problems in daily life" were significantly lower after the intervention program. The most liked contents were exercise $(12 / 20,60 \%)$, cooking $(12 / 20,60 \%)$, and nutrition $(10 / 20,50 \%)$ whereas the most dislike were exercise $(5 / 20,25 \%)$ and questionnaires $(2 / 20,10 \%)$. The main difficulties on using the TV app were "difficult in the access or manage the app" $(6 / 20$, $30 \%)$ and "lack of time" (4/20, 20\%). 
Table 2. Acceptability and feasibility of the television app intervention program $(n=21)^{\mathrm{a}}$.

\begin{tabular}{|c|c|c|c|c|}
\hline Characteristics & $\begin{array}{l}\text { Baseline }^{\mathrm{b}}, \text { median } \\
\text { (IQR) }\end{array}$ & $\begin{array}{l}\text { 3-month follow-up } \\
\text { median (IQR) }\end{array}$ & $\begin{array}{l}\text { Difference }{ }^{\mathrm{b}}, \text { median } \\
\text { (IQR) }\end{array}$ & $P$ value \\
\hline \multicolumn{5}{|l|}{ Feasibility } \\
\hline Interest in using eHealth for treatment of food insecurity $(n=20)$ & $1.0(3.0)$ & $5.0(5.0)$ & $3.0(5.0)$ & $.01^{\mathrm{c}}$ \\
\hline Interest in using eHealth for other purposes $(\mathrm{n}=20)$ & $1.0(2.0)$ & $6.0(2.0)$ & $3.0(4.0)$ & $.03^{\mathrm{c}}$ \\
\hline \multicolumn{5}{|l|}{ Acceptability } \\
\hline \multicolumn{5}{|l|}{ Affective attitude } \\
\hline Desire to use $\mathrm{TV}^{\mathrm{d}}$ app in daily life $(\mathrm{n}=19)$ & $7.0(1.0)$ & $6.0(2.0)$ & $0.0(2.0)$ & .06 \\
\hline Interest in using TV app in daily life $(\mathrm{n}=20)$ & $7.0(1.0)$ & $6.0(2.0)$ & $0.0(2.0)$ & $.02^{\mathrm{c}}$ \\
\hline Attractiveness of using the TV app in daily life $(\mathrm{n}=19)$ & $7.0(0.0)$ & $6.0(3.0)$ & $0.0(1.0)$ & $.04^{\mathrm{c}}$ \\
\hline $\begin{array}{l}\text { Advantages of using the TV app are or were higher than } \\
\text { disadvantages }(n=19)\end{array}$ & $7.0(0.0)$ & $6.0(3.0)$ & $-1.0(3.0)$ & $.01^{\mathrm{c}}$ \\
\hline \multicolumn{5}{|l|}{ Burden } \\
\hline Ease of using the TV app $(\mathrm{n}=21)$ & $7.0(1.0)$ & $6.0(3.0)$ & $-1.0(1.0)$ & .09 \\
\hline \multicolumn{5}{|l|}{ Ethicality } \\
\hline $\begin{array}{l}\text { Ethical appropriateness of using digital technologies for } \\
\text { treatment }(\mathrm{n}=20)\end{array}$ & $7.0(0.0)$ & $6.0(1.0)$ & $-1.0(1.0)$ & .08 \\
\hline $\begin{array}{l}\text { Acceptability of not including person-to-person interaction } \\
\text { in medical treatment }(n=20)\end{array}$ & $7.0(2.0)$ & $6.0(2.0)$ & $-1.0(2.0)$ & .30 \\
\hline $\begin{array}{l}\text { Suitability of using digital products to solve health problems } \\
(\mathrm{n}=18)\end{array}$ & $7.0(2.0)$ & $5.0(2.0)$ & $-2.0(3.0)$ & .08 \\
\hline $\begin{array}{l}\text { Generally in favor of using technologies to treat people } \\
(\mathrm{n}=20)\end{array}$ & $7.0(0.0)$ & $6.0(2.0)$ & $0.0(2.0)$ & .14 \\
\hline \multicolumn{5}{|l|}{ Perceived effectiveness } \\
\hline Utility of TV app ( $\mathrm{n}=19)$ & $7.0(0.0)$ & $6.0(2.0)$ & $0.0(2.0)$ & .10 \\
\hline $\begin{array}{l}\text { Ability of TV app to solve challenges or problems in daily } \\
\text { life }(n=16)\end{array}$ & $7.0(0.0)$ & $5.0(1.0)$ & $-2.0(3.0)$ & $.002^{\mathrm{c}}$ \\
\hline \multicolumn{5}{|l|}{ Self-efficacy } \\
\hline Motivation to use digital products $(\mathrm{n}=20)$ & $7.0(1.0)$ & $7.0(2.0)$ & $0.0(0.75)$ & .17 \\
\hline Control over TV app $(\mathrm{n}=20)$ & $7.0(1.0)$ & $7.0(2.0)$ & $0.0(1.5)$ & .47 \\
\hline $\begin{array}{l}\text { Existence of circumstances beyond control that prevent use } \\
\text { of TV app }(n=20)\end{array}$ & $7.0(1.0)$ & $6.5(4.0)$ & $0.0(2.5)$ & .05 \\
\hline
\end{tabular}

\section{${ }^{\text {a }}$ Sample size is not constant due to missing data. \\ ${ }^{\mathrm{c}} P<.05$. \\ ${ }^{\mathrm{d}} \mathrm{TV}$ : television. \\ Food Insecurity, Quality of Life, Physical Function, and Nutritional Status}

${ }^{\mathrm{b}}$ Items rated on a 7-point Likert scale from 1 (strongly negative/completely disagree) to 7 (strongly positive/completely agree).

Table 3 presents the changes in food insecurity, quality of life, physical function, and nutritional status. The intervention program significantly reduced food insecurity status and severity at the 3-month follow-up, at which point most participants who maintained food insecurity were classified into the low food insecurity subgroup. Regarding quality of life, the intervention had no impact on EQ-5D-3L, but significantly improved the FACIT-F scores. Regarding physical function, there was a significant improvement in HAQ, EMS, and regularity of exercise practice. No differences were found in hand grip strength after the intervention. Regarding nutritional status, adherence to MD did not change. 
Table 3. Effects of the intervention program on food insecurity, quality of life, physical function, and nutritional status $(\mathrm{N}=31)^{\mathrm{a}}$.

\begin{tabular}{|c|c|c|c|c|}
\hline Characteristics & Baseline & 3-month follow-up & Difference & $P$ value \\
\hline Food security $(\mathrm{n}=30), \mathrm{n}(\%)$ & $0(0)$ & $12(40)$ & $12(40)$ & $.001^{\mathrm{b}}$ \\
\hline Food insecurity, n (\%) & $30(100)$ & $18(60)$ & $-12(40)$ & $\mathrm{N} / \mathrm{A}^{\mathrm{c}}$ \\
\hline Low food insecurity & $26(87)$ & $17(57)$ & $-9(30)$ & \\
\hline Moderate food insecurity & $3(10)$ & $0(0)$ & $-3(10)$ & \\
\hline Severe food insecurity & $1(3)$ & $1(3)$ & $0(0)$ & \\
\hline \multicolumn{5}{|l|}{ Quality of life, mean (SD) } \\
\hline EQ-5D-3L ${ }^{\mathrm{d}}(\mathrm{n}=23)$ & $0.62(0.29)$ & $0.65(0.30)$ & $0.03(0.26)$ & .58 \\
\hline FACIT- $^{\mathrm{e}}(\mathrm{n}=31)$ & $38.52(9.32)$ & $41.96(10.00)$ & $3.82(8.27)$ & $.02^{\mathrm{b}}$ \\
\hline \multicolumn{5}{|l|}{ Physical function } \\
\hline $\mathrm{HAQ}^{\mathrm{f}}(\mathrm{n}=23)$, mean $(\mathrm{SD})$ & $0.77(0.70)$ & $0.55(0.60)$ & $-0.22(0.38)$ & $.01^{\mathrm{b}}$ \\
\hline $\operatorname{EMS}^{\mathrm{g}}(\mathrm{n}=10)$, mean $(\mathrm{SD})$ & $19.70(0.67)$ & $18.20(1.23)$ & $-1.50(1.08)$ & $.01^{\mathrm{b}}$ \\
\hline Hand grip strength $(\mathrm{n}=10)$, mean $(\mathrm{SD})$ & $29.35(7.52)$ & $30.87(10.44)$ & $1.52(3.72)$ & .21 \\
\hline \multicolumn{5}{|l|}{ Regular exercise $(\mathrm{n}=31), \mathrm{n}(\%)$} \\
\hline Yes & $10(32)$ & $18(58)$ & $8(26)$ & $.02^{\mathrm{b}}$ \\
\hline \multicolumn{4}{|c|}{ Days physically active in the last week (45-minutes duration; $n=31), n(\%)$} & N/A \\
\hline None & $24(77)$ & $16(52)$ & $-8(26)$ & \\
\hline $1-2$ & $3(10)$ & $8(26)$ & $5(16)$ & \\
\hline $3-4$ & $1(3)$ & $4(13)$ & $3(10)$ & \\
\hline$\geq 5$ & $3(10)$ & $3(10)$ & $0(0)$ & \\
\hline \multicolumn{5}{|l|}{ Nutritional status } \\
\hline PREDIMED $^{\text {h }}(\mathrm{n}=21), \mathrm{n}(\%)$ & & & & .99 \\
\hline Low adherence to $\mathrm{MD}^{\mathrm{i}}$ & $19(90)$ & $19(90)$ & $0(0)$ & \\
\hline High adherence to MD & $2(10)$ & $2(10)$ & $0(0)$ & \\
\hline
\end{tabular}

${ }^{\text {a }}$ Sample size is not constant due to missing data.

${ }^{\mathrm{b}} P<.05$.

${ }^{\mathrm{c}} \mathrm{N} / \mathrm{A}$ : not applicable.

${ }^{d}$ EQ-5D-3L: European quality of life questionnaire with five dimensions and three levels.

${ }^{\mathrm{e}}$ FACIT-F: Functional Assessment of Chronic Illness Therapy-Fatigue.

${ }^{\mathrm{f}} \mathrm{HAQ}$ : Health Assessment Questionnaire.

${ }^{g}$ EMS: Elderly Mobility Scale.

${ }^{\mathrm{h}}$ PREDIMED: Prevención con Dieta Mediterránea.

${ }^{\mathrm{i}} \mathrm{MD}$ : Mediterranean diet.

\section{Discussion}

\section{Principal Findings}

To the best of our knowledge, this is the first study to test an eHealth intervention program for older adults who have food insecurity, which is a vulnerable population that is historically not exposed to health innovation. Before implementing a full-scale trial, we conducted this pilot study to explore the feasibility and acceptability of a multidisciplinary 12-week home-based intervention program focusing on improving dietary and physical activity through an interactive TV app. The results of this pilot study reveal aspects of the intervention that may need modification before moving to a full-scale trial to evaluate its effectiveness. This methodology is suggested whenever complex health interventions are developed and implemented in real-life settings [27]. Overall, the intervention program is feasible and highly acceptable. Our findings also provide insights into the promising effects of eHealth interventions on food insecurity, fatigue, and physical function.

During the recruitment period, 177 older adults meeting the eligibility criteria were identified; however, only $17.5 \%$ (31/177) were enrolled in the intervention program. This adherence rate was lower than initially anticipated [26] and can be explained by different reasons. First, our recruitment was restricted to 
selected primary health care centers during a specific period. Thus, we may have identified only those individuals for whom access to health care was not a problem, which may explain their low interest and motivation to engage in an eHealth intervention program at baseline. In addition, a recent study in a Portuguese context reported that older adults with food insecurity admit to reducing their medical visits and stopping medication for economic reasons [9]. Thus, a potential lack of awareness and low prioritization of managing food insecurity may reflect older adults' need to prioritize other activities perceived as more important. Thus, it might be important to broaden our recruitment strategy in future trials [46-49]. One excellent indicator for a future study, however, was that no participants were lost to follow-up during the study period. This retention rate contrasts with the dropout rate of $45 \%$ at the 3-month follow-up found by Van Doorn-Van Atten et al [47] in another study on the feasibility of an eHealth intervention targeting the nutritional status of vulnerable elderly people. Overall, our results suggest that when elderly individuals agree to participate, their engagement with the study will not be a barrier to trial completion.

A similar reason could explain our results regarding one of the primary study outcomes: the feasibility of the intervention program. Our monitoring protocol showed that all participants used the TV app; however, 32\% (10/31) self-reported low use at the 3-month follow-up. Knowing that participant compliance is a common barrier to eHealth interventions [16], we integrated several strategies to monitor use and help participants remember to use the TV app (ie, monitoring the number of times participants accessed the TV app, technological reminders, phone calls, and questionnaires). However, these strategies are insufficient, which may present a challenge for future studies. To improve the monitoring process and thus increase participants' compliance, an emerging strategy is the use of pedometers or accelerometers, which have the potential to objectively and continuously monitor patients and inform researchers about participants' compliance with physical activity or exercise programs [20,21]. However, the adoption of this strategy in the present intervention program could complicate an already complex intervention while considering the characteristics of the end users, without guaranteeing that participants will use the monitoring instruments during their exercises or daily routine activities.

The baseline lack of participants' interest in using the TV app may be another explanation for self-reported low use. Even those participants who self-reported consistent use of the TV app stated that they had low interest in eHealth interventions in the baseline assessment. Nonetheless, after the intervention, we observed a substantial increase in participants' interest in eHealth interventions, both for improving food insecurity and for other purposes. This important result clearly justifies future investment in health innovation for this population.

In line with our feasibility results, the intervention program was highly accepted by participants both before and after the intervention. Acceptability, a multifaceted construct that reflects the extent to which people receiving a health care intervention consider it to be appropriate based on anticipated or experienced cognitive and emotional responses, was evaluated using constructs suggested by the theoretical framework of acceptability [37]. As expected, some of these constructs showed a significant decrease between the baseline and 3-month follow-up. Our eHealth intervention comprises a highly innovative digital program directed toward a vulnerable older adult population with low educational and socioeconomic status, low digital literacy, and a lack of regular exposure to health innovation, which are well-known barriers to eHealth adoption and implementation [24]. Thus, we anticipated that an innovative digital intervention would initially be met with high levels of acceptability. Later, however, as the intervention program involved active participation and commitment to physical exercise and a healthy diet, a decline in acceptability was observed. Despite this decrease, the median values of all acceptability constructs remained very high after the intervention.

Comparison of the present results with those of previous studies on the feasibility and acceptability of eHealth interventions focused on nutrition and physical activity among vulnerable older adults is challenging. The small number of previous studies and the high degree of heterogeneity in their designs, samples, interventions, and methods makes any comparison complex. Even so, our feasibility and acceptability results appear to be superior to those reported by Kraft et al [49] and Van Doorn-Van Atten et al [47].

Although impact analysis was not the primary objective of this study, the observed changes in key clinical outcomes revealed very promising short-term effects that support future randomized controlled trials. To the best of our knowledge, this is the first behavior change eHealth intervention that appears to effectively reduce food insecurity status and severity in a sample of older adults. The intervention program also showed improved fatigue and physical function of the participants, including their functional status, performance and mobility, and regularity of exercise. These results are in line with previous systematic reviews showing the effectiveness of eHealth interventions in improving the physical activity and physical functioning of older populations [20,21]. However, despite the systematic review by Marx et al [19] showing that eHealth malnutrition-related interventions improve the HRQoL and nutritional status of older adults, our intervention had no effect on these outcomes. These results could be explained by factors such as older age and greater physical, social, and economic vulnerabilities of our sample combined with the short follow-up period and use of a single instrument to evaluate the nutritional status. Longer follow-up periods and additional instruments for evaluating nutritional status (eg, 24-hour dietary recalls) should be considered for future effectiveness analysis.

\section{Strengths and Limitations}

This study has several limitations that need to be addressed in future full-scale trials. First, the low adherence of older adults may reflect selection bias. In addition to the large number of individuals who did not agree to participate in the study, 21 individuals were excluded because of technological problems with the installation of the TV app, which is an important limitation that needs to be addressed in future studies. Second, our feasibility and acceptability analyses were based exclusively 
on quantitative data collected through a structured questionnaire. The collection of qualitative data using semistructured interviews or focus groups could provide more detailed insights into participants' perspectives and thus reveal additional important aspects of the intervention in need of modification. Third, our short follow-up period prevented the analysis of the long-term effects of the intervention program. Fourth, the absence of a control group and the nonrandomized design of our study did not allow us to analyze the causal effects of the intervention program or to explore important feasibility aspects in preparation for a future randomized clinical trial, such as the randomization process and blinded outcome assessment. Finally, our pilot study involved a high proportion of missing data for almost all outcomes, which may compromise some of the data analysis performed.

Despite these limitations, this study's results can inform potential strategies for mitigating a growing global public health problem, which is expected to reach historic levels because of the COVID-19 pandemic [5,6]. Moreover, this pandemic is expected to cause an unprecedented social and economic crisis with devastating consequences for the most vulnerable populations [5,6]. Thus, there is an urgent need to develop feasible, acceptable, and effective interventions to promote healthy lifestyles and enhance well-being and quality of life among older adults. Our study represents the first step toward designing an effective intervention. Its strengths include the real-life health care context from which participants were recruited and the use of a validated instrument from the USDA Household Food Security Survey Module to identify eligible participants [29], which increases the external validity of our study. In addition, the study design was based on international frameworks for the design and implementation of complex and innovative interventions [27,28] and the assessment of acceptability constructs [37]. The strengths of this eHealth intervention program include (1) the early involvement of a multidisciplinary team and TV app end users in the development of the intervention program; (2) a multicomponent program aimed at improving several health outcomes (ie, nutritional, physical, and quality of life) based on behavioral change techniques; (3) use of a familiar ICT in participants' daily lives; and (4) close monitoring by the research team during the intervention period.

\section{Conclusions}

In conclusion, the findings of this pilot study reveal that our multidisciplinary 12-week home-based eHealth intervention program is a feasible and highly accepted method for improving the dietary and physical activity of older adults using a TV app, thus supporting a future full-scale trial. This intervention program not only reduced the proportion of older adults with food insecurity but also improved their fatigue and physical function.

\section{Acknowledgments}

This study was financed by national funds through the Foundation for Science and Technology, within the scope of the project DSAIPA/AI/0106/2019.

\section{Conflicts of Interest}

None declared.

\section{References}

1. Food and Agriculture Organization of the United Nations. The State of Food Security and Nutrition in the World 2019: Safeguarding against economic slowdowns and downturns. In: The State of Food Security and Nutrition in the World. New York, United States: United Nations; 2019:1-237 URL: http://www.fao.org/3/ca5162en/ca5162en.pdf

2. Coleman-Jensen A, Rabbitt MP, Smith MD, Gregory C, Singh A. Household food security in the United States in 2019. ERR-275, U.S. Department of Agriculture, Economic Research Service 2020 Sep:1-39 [FREE Full text]

3. Bickel G, Nord M, Price C, Hamilton W, Cook J. Guide to Measuring Household Food Security Revised 2000. Measuring Food Security in the United States. 2000. URL: https://fns-prod.azureedge.net/sites/default/files/FSGuide.pdf [accessed 2021-08-04]

4. Smith MD, Rabbitt MP, Coleman- Jensen A. Who are the world's food insecure? New evidence from the Food and Agriculture Organization's food insecurity experience scale. World Development 2017 May;93:402-412. [doi: 10.1016/j.worlddev.2017.01.006]

5. Gundersen C, Hake M, Dewey A, Engelhard E. Food insecurity during COVID-19. Appl Econ Perspect Policy 2020 Oct 02:13100 [FREE Full text] [doi: 10.1002/aepp.13100] [Medline: 33042509]

6. Wolfson JA, Leung CW. Food insecurity during COVID-19: an acute crisis with long-term health implications. Am J Public Health 2020 Dec;110(12):1763-1765. [doi: 10.2105/AJPH.2020.305953] [Medline: 32970451]

7. Fitzpatrick K, Harris C, Drawve G. Assessing U.S. Food Insecurity in the United States During COVID-19 Pandemic. 2020. URL: https://fulbright.uark.edu/departments/sociology/research-centers/community-family-institute/_resources/ community-and-family-institute/revised-assessing-food-insecurity-brief.pdf [accessed 2021-08-04]

8. Gregório MJ, Rodrigues AM, Graça P, de Sousa RD, Dias SS, Branco JC, et al. Food insecurity is associated with low adherence to the Mediterranean diet and adverse health conditions in Portuguese adults. Front Public Health 2018;6:38 [FREE Full text] [doi: 10.3389/fpubh.2018.00038] [Medline: 29515992] 
9. Fernandes SG, Rodrigues AM, Nunes C, Santos O, Gregório MJ, de Sousa RD, et al. Food insecurity in older adults: Results from the Epidemiology of Chronic Diseases Cohort Study 3. Front Med (Lausanne) 2018;5:203 [FREE Full text] [doi: 10.3389/fmed.2018.00203] [Medline: 30050904]

10. Hashemi R, Motlagh AD, Heshmat R, Esmaillzadeh A, Payab M, Yousefinia M, et al. Diet and its relationship to sarcopenia in community dwelling Iranian elderly: a cross sectional study. Nutrition 2015 Jan;31(1):97-104. [doi:

10.1016/j.nut.2014.05.003] [Medline: 25441592]

11. Arenas DJ, Thomas A, Wang J, DeLisser HM. A systematic review and meta-analysis of depression, anxiety, and sleep disorders in US adults with food insecurity. J Gen Intern Med 2019 Dec;34(12):2874-2882 [FREE Full text] [doi: 10.1007/s11606-019-05202-4] [Medline: 31385212]

12. Russell J, Flood V, Yeatman H, Mitchell P. Prevalence and risk factors of food insecurity among a cohort of older Australians. J Nutr Health Aging 2014 Jan;18(1):3-8. [doi: 10.1007/s12603-013-0339-6] [Medline: 24402381]

13. Portela-Parra ET, Leung CW. Food insecurity is associated with lower cognitive functioning in a national sample of older adults. J Nutr 2019 Oct 01;149(10):1812-1817 [FREE Full text] [doi: 10.1093/jn/nxz120] [Medline: 31240308]

14. Kihlström L, Burris M, Dobbins J, McGrath E, Renda A, Cordier T, et al. Food insecurity and health-related quality of life: a cross-sectional analysis of older adults in Florida, U.S. Ecol Food Nutr 2019;58(1):45-65. [doi:

10.1080/03670244.2018.1559160] [Medline: 30582362]

15. Global Observatory for eHealth. World Health Organization. 2018. URL: https://www.who.int/observatories/ global-observatory-for-ehealth [accessed 2021-08-04]

16. van Den Berg N, Schumann M, Kraft K, Hoffmann W. Telemedicine and telecare for older patients- a systematic review. Maturitas 2012 Oct;73(2):94-114. [doi: 10.1016/j.maturitas.2012.06.010] [Medline: 22809497]

17. Eysenbach G. What is e-health? J Med Internet Res 2001 Jun;3(2):E20. [doi: 10.2196/jmir.3.2.e20] [Medline: 11720962]

18. Takemoto M, Manini TM, Rosenberg DE, Lazar A, Zlatar ZZ, Das SK, et al. Diet and activity assessments and interventions using technology in older adults. Am J Prev Med 2018 Oct;55(4):105-115 [FREE Full text] [doi:

10.1016/j.amepre.2018.06.005] [Medline: 30241621]

19. Marx W, Kelly JT, Crichton M, Craven D, Collins J, Mackay H, et al. Is telehealth effective in managing malnutrition in community-dwelling older adults? A systematic review and meta-analysis. Maturitas 2018 May;111:31-46. [doi: 10.1016/j.maturitas.2018.02.012] [Medline: 29673830]

20. Muellmann S, Forberger S, Möllers T, Bröring E, Zeeb H, Pischke CR. Effectiveness of eHealth interventions for the promotion of physical activity in older adults: a systematic review. Prev Med 2018 Mar;108:93-110. [doi: 10.1016/j.ypmed.2017.12.026] [Medline: 29289643]

21. Stockwell S, Schofield P, Fisher A, Firth J, Jackson SE, Stubbs B, et al. Digital behavior change interventions to promote physical activity and/or reduce sedentary behavior in older adults: a systematic review and meta-analysis. Exp Gerontol 2019;120:68-87. [doi: 10.1016/j.exger.2019.02.020] [Medline: $\underline{30836130]}$

22. Yadav L, Haldar A, Jasper U, Taylor A, Visvanathan R, Chehade M, et al. Utilising digital health technology to support patient-healthcare provider communication in fragility fracture recovery: systematic review and meta-analysis. Int J Environ Res Public Health 2019 Oct 22;16(20):1-22 [FREE Full text] [doi: 10.3390/ijerph16204047] [Medline: $\underline{31652597]}$

23. Inglis SC, Clark RA, Dierckx R, Prieto-Merino D, Cleland JG. Structured telephone support or non-invasive telemonitoring for patients with heart failure. Cochrane Database Syst Rev 2015(10):CD007228. [doi: 10.1002/14651858.CD007228.pub3] [Medline: 26517969]

24. Hage E, Roo JP, van Offenbeek MA, Boonstra A. Implementation factors and their effect on e-Health service adoption in rural communities: a systematic literature review. BMC Health Serv Res 2013;13:19 [FREE Full text] [doi: 10.1186/1472-6963-13-19] [Medline: 23311452]

25. Depp CA, Schkade DA, Thompson WK, Jeste DV. Age, affective experience, and television use. Am J Prev Med 2010 Aug;39(2):173-178 [FREE Full text] [doi: 10.1016/j.amepre.2010.03.020] [Medline: 20621265]

26. Rodrigues AM, Gregório MJ, Gein P, Eusébio M, Santos MJ, de Sousa RD, et al. Home-based intervention program to reduce food insecurity in elderly populations using a TV app: study protocol of the randomized controlled trial Saúde.come senior. JMIR Res Protoc 2017 Mar 13;6(3):e40 [FREE Full text] [doi: 10.2196/resprot.6626] [Medline: 28288956]

27. Craig P, Dieppe P, Macintyre S, Michie S, Nazareth I, Petticrew M, Medical Research Council Guidance. Developing and evaluating complex interventions: the new Medical Research Council guidance. Br Med J 2008 Sep 29;337:a1655 [FREE Full text] [doi: 10.1136/bmj.a1655] [Medline: 18824488 ]

28. Stilgoe J, Owen R, Macnaghten P. Developing a framework for responsible innovation. Res Policy 2013 Nov;42(9):1568-1580. [doi: 10.1016/j.respol.2013.05.008]

29. Gregório M, Graça P, Nogueira P, Gomes S, Santos C, Boavida J. Proposta Metodológica para a Avaliação da Insegurança Alimentar em Portugal. Rev Nutrícias. 2014. URL: https://repositorio.ul.pt/handle/10451/17617 [accessed 2021-08-04]

30. Prochaska JO, DiClemente CC, Norcross JC. In search of how people change. Applications to addictive behaviors. Am Psychol 1992 Sep;47(9):1102-1114. [doi: 10.1037//0003-066x.47.9.1102] [Medline: 1329589]

31. Gregório MJ, Rodrigues AM, Eusébio M, Sousa RD, Dias S, André B, et al. Dietary patterns characterized by high meat consumption are associated with other unhealthy life styles and depression symptoms. Front Nutr 2017;4:25 [FREE Full text] [doi: 10.3389/fnut.2017.00025] [Medline: 28660194] 
32. Portuguese Food Balance - 2012 - 2016. Instituto Nacional de Estatística. 2017. URL: https://www.ine.pt/xportal/ xmain?xpid=INE\&xpgid=ine publicacoes\&PUBLICACOESpub boui=289818234\&PUBLICACOESmodo=2 [accessed 2021-08-04]

33. Santos DM, Rodrigues SS, de Oliveira BM, Vaz de Almeida MD. Diet quality in elderly Portuguese households. J Nutr Health Aging 2014 Mar;18(3):243-250. [doi: 10.1007/s12603-013-0431-y] [Medline: 24626750]

34. A Saúde dos Portugueses. Perspetiva 2015. Direção-Geral da Saúde. 2015. URL: https://www.omd.pt/content/uploads/ 2017/12/dgs-saude-portugueses-2015.pdf [accessed 2021-08-04]

35. Trust for America's Health. Recommendations to Promote Health and Well-being Among Aging Populations. Washington, D.C: Altarum Institute; 2012.

36. Pais-Ribeiro J, Silva I, Ferreira T, Martins A, Meneses R, Baltar M. Validation study of a Portuguese version of the Hospital Anxiety and Depression Scale. Psychol Health Med 2007 Mar;12(2):225-235. [doi: 10.1080/13548500500524088] [Medline: 17365902]

37. Sekhon M, Cartwright M, Francis JJ. Acceptability of healthcare interventions: an overview of reviews and development of a theoretical framework. BMC Health Serv Res 2017 Jan 26;17(1):88 [FREE Full text] [doi: 10.1186/s12913-017-2031-8] [Medline: 28126032]

38. Ferreira LN, Ferreira PL, Pereira LN, Oppe M. EQ-5D Portuguese population norms. Qual Life Res 2014 Mar 3;23(2):425-430. [doi: 10.1007/s11136-013-0488-4] [Medline: 23912856]

39. Ferreira LN, Ferreira PL, Pereira LN, Oppe M. The valuation of the EQ-5D in Portugal. Qual Life Res 2014 Mar 8;23(2):413-423. [doi: 10.1007/s11136-013-0448-z] [Medline: 23748906]

40. Chandran V, Bhella S, Schentag C, Gladman DD. Functional assessment of chronic illness therapy-fatigue scale is valid in patients with psoriatic arthritis. Ann Rheum Dis 2007 Jul;66(7):936-939 [FREE Full text] [doi: 10.1136/ard.2006.065763] [Medline: 17324972]

41. Santos R, Reis P, Rebelo L, Dias F, Rosa C, Queiroz M. "Health Assessment Questionnaire" (versão curta): adaptação para língua portuguesa e estudo da sua aplicabilidade. Acta Reuma Port 1996;76:21-26 [FREE Full text]

42. Fries JF, Spitz P, Kraines RG, Holman HR. Measurement of patient outcome in arthritis. Arthritis Rheum 1980 Feb;23(2):137-145. [doi: 10.1002/art.1780230202] [Medline: 7362664]

43. Santos A, Ramos N, Estêvão P, Lopes A, Pascoalinho J. Instrumentos de Medida Úteis no Contexto da Avaliação em Fisioterapia. Re(habilitar)-Revista da ESSA. 2005. URL: https://scholar.google.com/ citations?view op=view citation\&hl=pt-BR\&user=MJN-oH0AAAAJ\&citation for view=MJN-oH0AAAAJ:isU91gLudPYC [accessed 2021-08-04]

44. Yu MS, Chan CC, Tsim RK. Usefulness of the Elderly Mobility Scale for classifying residential placements. Clin Rehabil 2007 Dec;21(12):1114-1120. [doi: 10.1177/0269215507080789] [Medline: 18042607]

45. Schröder H, Fitó M, Estruch R, Martínez-González MA, Corella D, Salas-Salvadó J, et al. A short screener is valid for assessing Mediterranean diet adherence among older Spanish men and women. J Nutr 2011 Jun;141(6):1140-1145 [FREE Full text] [doi: 10.3945/jn.110.135566] [Medline: 21508208]

46. van Doorn-van Atten MN, de Groot LC, Romea AC, Schwartz S, de Vries JH, Haveman-Nies A. Implementation of a multicomponent telemonitoring intervention to improve nutritional status of community-dwelling older adults: a process evaluation. Public Health Nutr 2019 Feb;22(2):363-374. [doi: 10.1017/S1368980018002185] [Medline: $\underline{30175698]}$

47. van Doorn-van Atten MN, Haveman-Nies A, Heery D, de Vries JH, de Groot LC. Feasibility and effectiveness of nutritional telemonitoring for home care clients: a pilot study. Gerontologist 2019 Jan 09;59(1):158-166. [doi: 10.1093/geront/gny059] [Medline: 29860379]

48. Hirani SP, Beynon M, Cartwright M, Rixon L, Doll H, Henderson C, et al. The effect of telecare on the quality of life and psychological well-being of elderly recipients of social care over a 12-month period: the Whole Systems Demonstrator cluster randomised trial. Age Ageing 2014 May;43(3):334-341. [doi: 10.1093/ageing/aft185] [Medline: 24333802]

49. Kraft M, van den Berg N, Kraft K, Schmekel S, Gärtner S, Krüger J, et al. Development of a telemedical monitoring concept for the care of malnourished geriatric home-dwelling patients: a pilot study. Maturitas 2012 Jun;72(2):126-131. [doi: 10.1016/j.maturitas.2012.02.011] [Medline: 22440535]

\section{Abbreviations}

EMS: Elderly Mobility Scale

EQ-5D-3L: European Quality of Life Questionnaire with five dimensions and three levels

FACIT-F: Functional Assessment of Chronic Illness Therapy-Fatigue

HAQ: Health Assessment Questionnaire

HRQoL: health-related quality of life

ICT: information and communication technology

MD: Mediterranean diet

PREDIMED: Prevención con Dieta Mediterránea

TV: television 
USDA: United States Department of Agriculture

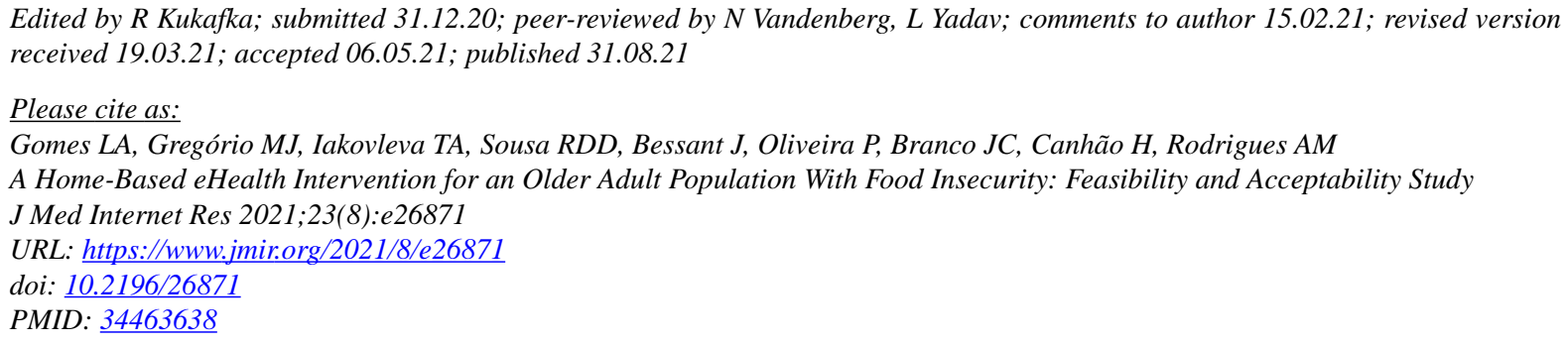

CLuís Antunes Gomes, Maria João Gregório, Tatiana A Iakovleva, Rute Dinis de Sousa, John Bessant, Pedro Oliveira, Jaime C Branco, Helena Canhão, Ana Maria Rodrigues. Originally published in the Journal of Medical Internet Research (https://www.jmir.org), 31.08.2021. This is an open-access article distributed under the terms of the Creative Commons Attribution License (https://creativecommons.org/licenses/by/4.0/), which permits unrestricted use, distribution, and reproduction in any medium, provided the original work, first published in the Journal of Medical Internet Research, is properly cited. The complete bibliographic information, a link to the original publication on https://www.jmir.org/, as well as this copyright and license information must be included. 